\title{
Comparison of different intubation techniques performed inside a moving ambulance: a manikin study
}

\author{
KB Wong, CT Lui, William YW Chan, TL Lau, Simon YH Tang, KL Tsui *
}

\section{A B S T R A C T}

Objective: Airway management and endotracheal intubation may be required urgently when a patient deteriorates in an ambulance or aircraft during interhospital transfer or in a prehospital setting. The objectives of this study were: (1) to compare the effectiveness of conventional intubation by Macintosh laryngoscope in a moving ambulance versus that in a static ambulance; and (2) to and GlideScope laryngoscopy with conventional intubation inside a moving ambulance.

Design: Comparative experimental study.

Setting: The experiment was conducted in an ambulance provided by the Auxiliary Medical Service in Hong Kong.

Participants: A group of 22 doctors performed endotracheal intubation on manikins with Macintosh laryngoscope in a static and moving ambulance. In addition, they performed conventional Macintosh intubation, inverse intubation with Macintosh laryngoscope, and GlideScope intubation in a moving ambulance in both normal and simulated difficult airways.

Main outcome measures: The primary outcome was the rate of successful intubation. The secondary outcomes were time taken for intubation, subjective glottis visualisation grading, and eventful intubation (oesophageal intubation, intubation time $>60$ seconds, and incisor breakage) with different techniques or devices.

A video showing different intubation techniques is available at $<w w w . h k m j$. org $>$. Macintosh intubation in a static ambulance (95.5\%), conventional intubation in a moving ambulance compare the effectiveness of inverse intubation

(95.5\%), as well as GlideScope intubation in a moving ambulance (95.5\%) were associated with high success rates; the success rate of inverse intubation was comparatively low (54.5\%; $\mathrm{P}=0.004)$. In difficult airways, conventional Macintosh intubation in a static ambulance (86.4\%), conventional intubation in a moving ambulance (90.9\%), and GlideScope intubation in a moving ambulance (100\%) were associated with high success rates; the success rate of inverse intubation was comparatively lower $(40.9 \%$; $\mathrm{P}=0.034)$.

Conclusions: En-route intubation in an ambulance by conventional Macintosh laryngoscopy is superior to inverse intubation unless the cephalad access is impossible. GlideScope laryngoscopy appears to be associated with lower rates of eventful intubation in difficult airways and has better laryngoscopic view versus inverse intubation.

Hong Kong Med J 2014;20:304-12

DOI: $10.12809 / \mathrm{hkmj} 134168$

${ }^{1}$ KB Wong, MB, BS

${ }^{1}$ CT Lui, MB, BS, FHKAM (Emergency Medicine)

1,2 WYW Chan, BSc (Hons), MScPEC

${ }^{2}$ TL Lau, MBA, B Bus (HRM)

${ }^{1}$ SYH Tang, FRCSEd, FHKAM (Emergency Medicine)

1,2 KL Tsui *, FRCSEd, FHKAM (Emergency Medicine)

Department of Accident and Emergency, Tuen Mun Hospital, Tuen Mun, Hong Kong

2 Auxiliary Medical Service, AMS Headquarters, 81 Princess Margaret Road, Hong Kong

* Corresponding author: tsuikl@ha.org.hk

New knowledge added by this study

The intubation success rates with conventional Macintosh laryngoscopy in static and moving ambulances were high.

- The high failure rate and prolonged time associated with inverse intubation technique made it less useful for en-route intubation unless the cephalad access of the patient was not feasible.

- The study demonstrated high intubation success rate of and slightly longer intubation time with GlideScope intubation in a moving ambulance. GlideScope intubation was associated with lower rates of eventful intubation versus inverse intubation in the setting of difficult airways.

Implications for clinical practice or policy

- En-route intubation in an ambulance using conventional Macintosh laryngoscopy at a speed of $20 \mathrm{~km} / \mathrm{h}$ can be considered a viable option, especially when stopping the transport vehicle is impossible and dangerous.

- The use of video-assisted airway management (GlideScope) could be a backup plan for en-route intubation in the setting of difficult airways, if available. 


\section{Introduction}

Airway management may be required urgently when a patient deteriorates in an ambulance during interhospital transfer or in a prehospital setting. En-route intubation in an ambulance is challenging due to patient and environmental factors. ${ }^{1}$ These may include inadequate or over-exposed lighting, limited access to the patient, a continuously moving environment, confined space, and unanticipated patient deterioration. The success rate of en-route intubation $(89.6 \%)$ is lower than that of hospital intubation (98.8\%) and intubation-on-scene (94.9\%) in air medical transport. ${ }^{2}$ Intubation success is more likely in a hospital setting (odds ratio $[\mathrm{OR}]=8.70$ ) or at the scene $(\mathrm{OR}=2.3)$ compared with en-route intubation. $^{2}$

Some studies ${ }^{3,4}$ suggest using inverse intubation in an entrapped or confined environment. In inverse intubation, the intubator crouches or kneels near the patient's right side, while holding the laryngoscope in the right hand. Patient's mouth is opened with the intubator's left hand. The laryngoscope blade is gently pulled up and towards the patient's feet at a $45^{\circ}$ angle. The endotracheal tube is passed between the visualised vocal cords. The success rate and time of intubation of using inverse intubation in air transport were not significantly different from those with conventional intubation in air transport..$^{5}$ Inverse intubation is particularly useful in circumstances where the cephalad access to the patient is limited. In addition, the mechanical advantages of pulling up the larynx with the dominant hand may, theoretically, facilitate visualisation of vocal cords of patients with difficult airways.

In recent years, portable video laryngoscope (GlideScope; Verathon Inc, Bothell [WA], US) was introduced to facilitate airway management in the prehospital setting. 6,7 GlideScope was the first commercially available video laryngoscope. It uses a high-resolution camera embedded into a plastic laryngoscope blade, and a LED light for illumination. The distal angulation makes it ideally suitable for visualising and intubating over the anterior larynx. The endotracheal tube has to be used with a special stylet to match the gentle curve of $60^{\circ}$ of the GlideScope blade. It has been proven to be a useful adjunct for intubation in both normal and difficult airways in selected settings. ${ }^{8-10}$

The objectives of our experimental study were: (1) to compare the effectiveness of conventional intubation by Macintosh laryngoscope in a moving ambulance versus that in a static ambulance; (2) to compare the effectiveness of inverse intubation and GlideScope laryngoscopy (model: GVL 4) with conventional intubation inside a moving ambulance.

\section{於行駛中的救護車內利用模型假人進行氣管插管 的比較研究}

黃冠斌、雷俊達、陳旭榮、劉庭亮、鄧耀鏗、徐國樑

目的：當病人被送往醫院或在被轉送的過程中, 不論在救護車內或在 飛機上, 如果情況危急便須立即替病人進行氣管插管。本研究旨在 （1）比較在行駛中與靜止的救護車內使用Macintosh喉鏡進行傳統 式插管的有效性, 以及（2）比較行駛中的救護車內進行逆向插管和 GlideScope喉鏡與傳統式插管的有效性。

設計：對比試驗研究。

安排：本實驗在香港醫療輔助隊提供的救護車內進行。

參與者：共22位醫生參與研究, 他們分別在靜止和行駛中的救護 車內使用Macintosh喉鏡為模型假人進行氣管插管。此外, 他們在 行駛中的救護車內分別為呼吸道正常及困難的擬真模型進行傳統式 Macintosh插管、Macintosh喉鏡進行逆行插管以及GlideScope插管。

主要結果測量：主要指標為插管成功率。次要指標為使用不同技術或 設備進行插管所需時間、主觀聲門可視化分級、因插管而導致的不良 事件（食管插管、插管時間超過60秒、門牙斷裂）。

結果: 在呼吸道正常的情況下, 在靜止的救護車內進行傳統式 Macintosh插管（95.5\%）、在行駛中的救護車內進行常規插管 (95.5\%) 和GlideScope插管 $(95.5 \%)$ 均有高成功率。而逆行插管的 成功率相對較低（54.5\%，P=0.004）。在呼吸道困難的情況下, 在靜 止的救護車內進行傳統式Macintosh插管 $(86.4 \%$ ) 、在行駛中的救護 車內進行常規插管 $(90.9 \%)$ 和GlideScope插管（100\%）均有高成功 率。而逆行插管的成功率相對較低（40.9\%，P=0.034）。

結論：與逆行插管比較, 除非不能觸及病人的頭側位置, 否則在救護 車上使用傳統式Macintosh喉鏡較佳。與逆行插管比較, GlideScope 喉鏡似乎在呼吸道困難的情況下因插管導致不良事件的發生率較低。 此外, GlideScope喉鏡有較佳的喉鏡觀察角度。

\section{Methods}

\section{Participants}

This was a comparative experimental study conducted from June to October 2012. Altogether, 22 doctors-including emergency medicine trainees, members, and fellows-were recruited to participate voluntarily in the study. All participants were working in the accident and emergency department (AED) and had been practising emergency medicine for at least 2 months. All of them had experience in performing endotracheal intubation in patients. The approval of ethics committee was considered waived as the study was performed on manikins and did not involve patients.

Demographic data of the participating doctors including age, gender, AED working experience, previous attendance of advanced airway training workshop, past experience of using inverse intubation and GlideScope on living or dead patients were collected. Advanced airway training workshop is a full-day course organised by the Hong Kong 
College of Emergency Medicine. Course attendants learn the basic skills of endotracheal intubation. Various airway adjuncts such as GlideScope are demonstrated and opportunities provided for participants to practise intubation with these during the course.

\section{Pre-experiment preparation}

The use of conventional Macintosh laryngoscopy, inverse intubation with Macintosh laryngoscope and GlideScope laryngoscopy were demonstrated to participants individually by the experiment conductor using an "AIRSIM" manikin at least 1 week before the study. The participants were allowed hands-on practice of the techniques and devices, freely, in a training room before the experiment.

\section{Experiment setting}

The experiment was conducted in an ambulance provided by the Auxiliary Medical Service. The ambulance we used was Mercedes-Benz 516CDI measuring approximately $1.6 \mathrm{~m}$ in width and $2.2 \mathrm{~m}$ in length. The stretcher, together with the manikin, was locked on the right side of the ambulance, as in real life. The intubator would have limited room to kneel down at the vertex of the patient to perform conventional Macintosh and GlideScope intubations (Fig 1). Inverse intubation was performed on the right side of the manikin (Fig 2). The ambulance was moving at a speed of $20 \mathrm{~km} /$ hour, following a fixed route chosen before the experiment within the hospital compound. Moving at this relatively slow speed was only possible on the chosen route as there were a number of turnarounds and road bumpers.

\section{Intubation setting}

The Laerdal "Adult Basic" manikin was used in the study. A neck collar was applied to the manikin to restrict the neck mobility and simulate a difficult airway. Size-3 blade was used for conventional Macintosh and inverse intubations. All intubations were performed with a 7.5-mm cuffed endotracheal tube. All participants performed intubations on the manikin in both normal and difficult airways inside a static ambulance and moving ambulance. Participants performed the conventional Macintosh, inverse Macintosh and GlideScope intubations in both normal and simulated difficult airways inside the moving ambulance in the same sequence. Neither external manipulation of the larynx nor airway management adjunct was allowed in the study.

The time required for intubation was recorded with electronic stopwatch and corrected to one decimal place. The start time was defined when the participant was asked to begin while sitting on the couch, approximately 1 metre from the manikin, with the equipment in hands. The end of the

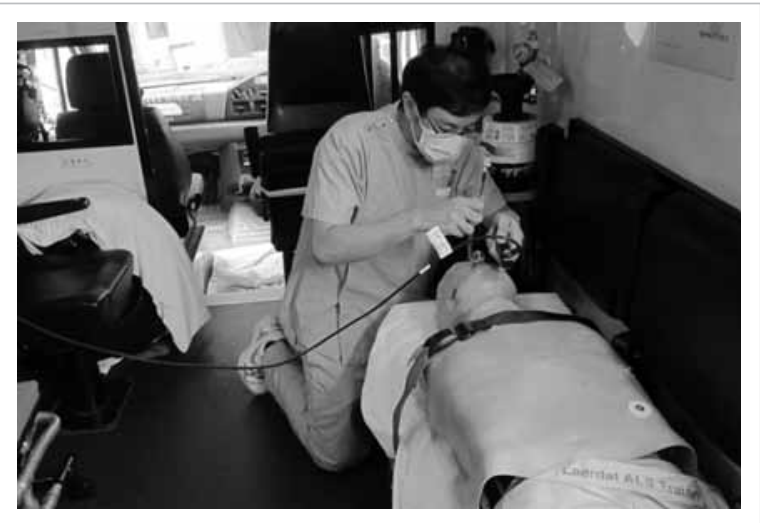

FIG I. Intubation in a confined space

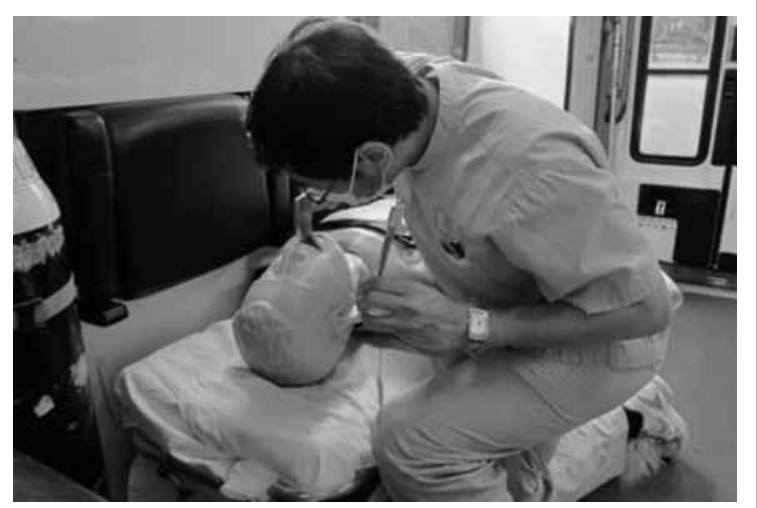

FIG 2. Inverse intubation performed on the right side

procedure was defined when the participant verbally stated that the airway was secured with inflation of the cuffed balloon of the endotracheal tube. The verification of the endotracheal tube placement was performed by direct visualisation and inflation of the artificial lung, with no air leakage from the manikin. Both oesophageal intubation and intubation with time taken longer than 60 seconds were considered to be unsuccessful procedures. Incisor breakage was reported by the participants when a "click" sound was heard during intubation; however, it was not considered an unsuccessful intubation. Participants also reported the Cormack-Lehane laryngoscopic grading system (C\&L grade; grade $1-4$ ) and their preferences for intubation techniques and devices. Eventful intubation was defined as incisor break, oesophageal intubation, or intubation taking longer than 60 seconds.

\section{Data analysis}

We used SPSS version 16.0 for Windows for statistical analysis. Rates of successful intubation and incisor breakage were presented in percentage. The working experience of participants and time 
spent on intubation were described by median and interquartile range as the data showed skewed distribution. The time required for intubation by different intubation techniques and devices were analysed by Wilcoxon signed rank test for paired data. The rates of successful intubation, complications including oesophageal intubation, incisor breakage and the subjective visualisation grading system

TABLE I. Baseline characteristics of the participant doctors $(\mathrm{n}=22)$

\begin{tabular}{|c|c|}
\hline Characteristics & Data* $^{*}$ \\
\hline Gender (male) & $17(77.3)$ \\
\hline Age (years) & $30.5 \pm 5.7$ \\
\hline A\&E experience (years) & $4.9 \pm 5.1$ \\
\hline Obtained Fellowship & $5(22.7)$ \\
\hline Obtained Membership & $9(40.9)$ \\
\hline $\begin{array}{l}\text { Participation in advance airway } \\
\text { management course training workshop }\end{array}$ & $14(63.6)$ \\
\hline \multicolumn{2}{|l|}{ Experience in using inverse intubation } \\
\hline Living patient & $1(4.5)$ \\
\hline Dead patient & $1(4.5)$ \\
\hline Manikin & $22(100.0)$ \\
\hline \multicolumn{2}{|l|}{ Experience in using GlideScope } \\
\hline Living patient & $8(36.4)$ \\
\hline Dead patient & $7(31.8)$ \\
\hline Manikin & $22(100.0)$ \\
\hline
\end{tabular}

Abbreviation: $A \& E$ = accident and emergency

* Data are presented as No. (\%) or mean \pm standard deviation among different intubation techniques and devices were compared using Fisher's exact test with or without Freeman-Halton extension. Spearman's correlation was employed to show the relationship between time of intubation and AED experience. The results were regarded as statistically significant if $\mathrm{P}<0.05$.

\section{Results}

A total of 22 AED (17 male and 5 female) doctors participated in the experiment. The median age of the participants was 30.5 years. The mean AED working experience of the participants was 4.9 years. As the technique and devices were demonstrated by the experiment conductor before beginning the experiment, all doctors had experience with using inverse intubation and GlideScope in a manikin. The details are shown in Table 1 . All participants performed intubations in the eight scenarios and the success rate of each scenario was summarised in Figure 3.

\section{Conventional intubation in static versus moving ambulance}

The percentage of successful and unsuccessful intubations, time required for intubation, subjective glottis visualisation score, and complication rates using conventional Macintosh intubation in static and moving ambulance are shown in Table 2 . In normal airways, the intubation success rates in both static (95.5\%) and moving ambulances (95.5\%) were high. The median intubation times for intubation in

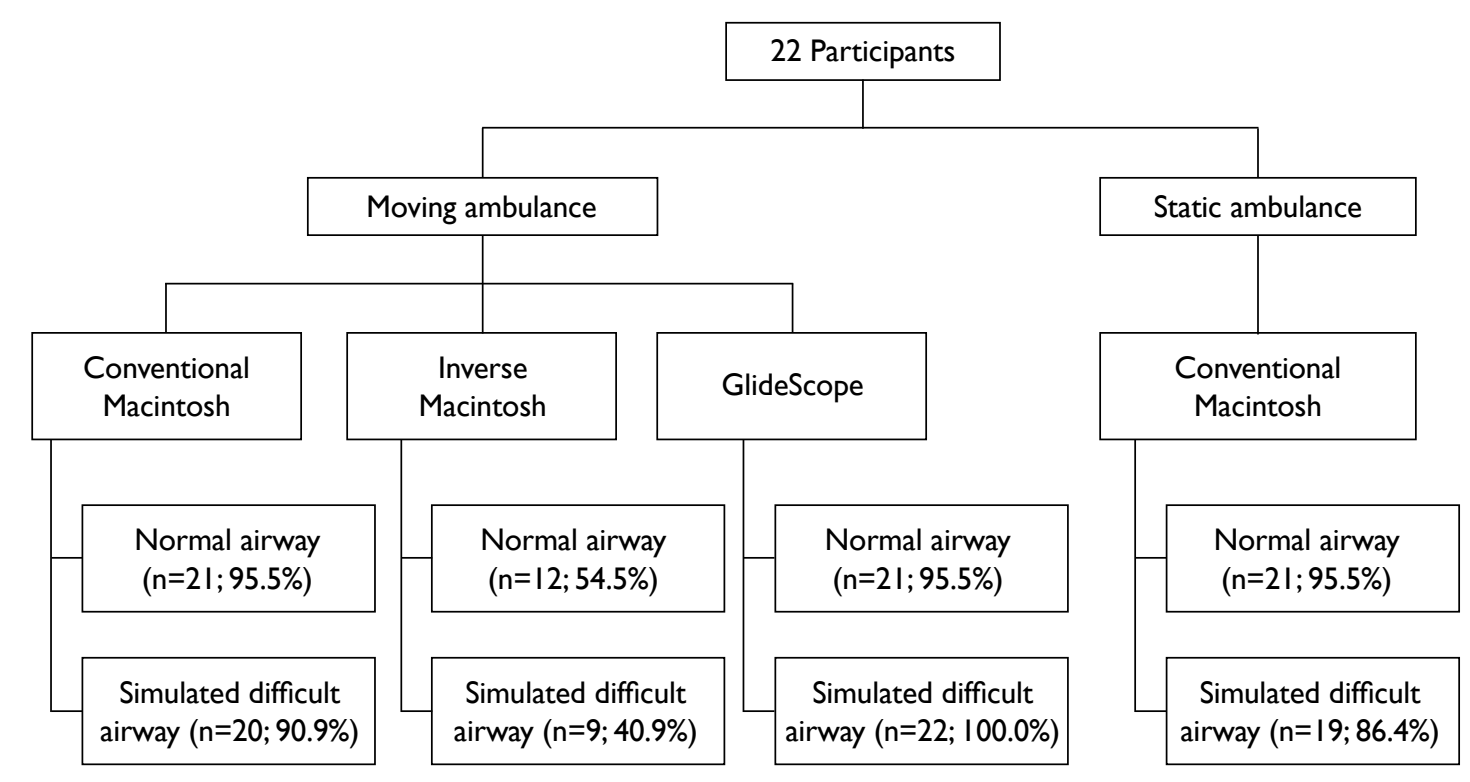

FIG 3. Flowchart of the experiment and primary outcomes in the experiment 
static and moving ambulances were 21.2 seconds and 26.5 seconds, respectively $(P=0.268)$. In difficult airways, the intubation success rates in static and moving ambulances were $86.4 \%$ and $90.9 \%$, respectively. The median intubation times in static and moving ambulances were 22.6 seconds and 20.6 seconds, respectively $(\mathrm{P}=0.488)$. There was no significant difference in the Cormack-Lehane grades and incidence of eventful intubation between the two groups.

\section{Conventional intubation versus inverse intubation in a moving ambulance}

The intubation performance using the conventional Macintosh laryngoscopy and inverse Macintosh intubation in a moving ambulance is shown in Table 3. In normal airways, the success rate of conventional

TABLE 2. Comparison of success rate, intubation time, glottis visualisation grading, and eventful intubation rate with conventional Macintosh intubation in static and moving ambulance

\begin{tabular}{|c|c|c|c|c|}
\hline & & $\begin{array}{l}\text { Static ambulance } \\
\qquad(\mathrm{n}=22)^{\star}\end{array}$ & $\begin{array}{l}\text { Moving ambulance } \\
\qquad(\mathrm{n}=22)^{\star}\end{array}$ & $P$ value \\
\hline \multirow[t]{7}{*}{ Normal airway } & Successful intubation $\leq 60$ seconds & $21(95.5)$ & $21(95.5)$ & 1 \\
\hline & Intubation time (seconds) & $21.2 \pm 16.5$ & $26.5 \pm 14.1$ & 0.268 \\
\hline & Cormack-Lehane grade 1/2/3/4 & $17 / 5 / 0 / 0$ & $16 / 6 / 0 / 0$ & 0.999 \\
\hline & Eventful intubation & $2(9.1)$ & $3(13.6)$ & 1 \\
\hline & Oesophageal intubation & 0 & 0 & 1 \\
\hline & Intubation time $>60$ seconds & $1(4.5)$ & $1(4.5)$ & 1 \\
\hline & Incisor breakage & $1(4.5)$ & $2(9.1)$ & 1 \\
\hline \multirow[t]{7}{*}{ Difficult airway } & Successful intubation $\leq 60$ seconds & $19(86.4)$ & $20(90.9)$ & 1 \\
\hline & Intubation time (seconds) & $22.6 \pm 9.4$ & $20.6 \pm 11.8$ & 0.488 \\
\hline & Cormack-Lehane grade 1/2/3/4 & $13 / 6 / 3 / 0$ & $12 / 7 / 3 / 0$ & 1 \\
\hline & Eventful intubation & $6(27.3)$ & $8(36.4)$ & 1 \\
\hline & Oesophageal intubation & $1(4.5)$ & $2(9.1)$ & 1 \\
\hline & Intubation time $>60$ seconds & $2(9.1)$ & 0 & 0.488 \\
\hline & Incisor breakage & $3(13.6)$ & $6(27.3)$ & 0.457 \\
\hline
\end{tabular}

* Data are presented as No., No. (\%), or median \pm interquartile range

TABLE 3. Comparison of success rate, intubation time, glottis visualisation grading, and eventful intubation rate with conventional Macintosh and inverse Macintosh intubation in a moving ambulance

\begin{tabular}{|c|c|c|c|c|}
\hline & & $\begin{array}{c}\text { Conventional } \\
\text { intubation }(n=22)^{*}\end{array}$ & $\begin{array}{l}\text { Inverse intubation } \\
\qquad(\mathrm{n}=22)^{\star}\end{array}$ & $P$ value \\
\hline \multirow[t]{7}{*}{ Normal airway } & Successful intubation $\leq 60$ seconds & $21(95.5)$ & $12(54.5)$ & 0.004 \\
\hline & Intubation time (seconds) & $26.5 \pm 14.1$ & $37.8 \pm 16.1$ & 0.043 \\
\hline & Cormack-Lehane grade $1 / 2 / 3 / 4$ & $16 / 6 / 0 / 0$ & $3 / 11 / 4 / 4$ & $<0.001$ \\
\hline & Eventful intubation $†$ & $3(13.6)$ & $18(81.8)$ & $<0.001$ \\
\hline & Oesophageal intubation & 0 & $9(40.9)$ & 0.001 \\
\hline & Intubation $>60$ seconds & $1(4.5)$ & $3(13.6)$ & 0.607 \\
\hline & Incisor breakage & $2(9.1)$ & $10(54.5)$ & 0.016 \\
\hline \multirow[t]{7}{*}{ Difficult airway } & Successful intubation $\leq 60$ seconds & $20(90.9)$ & $9(40.9)$ & 0.034 \\
\hline & Intubation time (seconds) & $20.6 \pm 11.8$ & $51.3 \pm 52.3$ & 0.002 \\
\hline & Cormack-Lehane grade $1 / 2 / 3 / 4$ & $12 / 7 / 3 / 0$ & $2 / 8 / 9 / 3$ & 0.003 \\
\hline & Eventful intubation $\ddagger$ & $8(36.4)$ & $18(81.8)$ & 0.002 \\
\hline & Oesophageal intubation & $2(9.1)$ & $7(31.8)$ & 0.132 \\
\hline & Intubation $>60$ seconds & 0 & $6(27.3)$ & 0.021 \\
\hline & Incisor breakage & $6(27.3)$ & $8(36.4)$ & 0.747 \\
\hline
\end{tabular}

* Data are presented as No., No. (\%), or median \pm interquartile range

$\dagger$ Include any one or more events; in four oesophageal intubation cases, incisor breakages are also reported

$\ddagger$ Include any one or more events; in three oesophageal intubation cases, incisor breakages are also reported 
intubation (95.5\%) was significantly higher than that of inverse intubation (54.5\%; $\mathrm{P}=0.004)$. The median intubation time with the conventional technique (26.5 seconds) was shorter than that with inverse intubation (37.8 seconds; $\mathrm{P}=0.043$ ). The number of difficult laryngeal visualisation (ie CormackLehane grade $\geq 3$ ) was significantly higher with inverse intubation technique $(n=8 ; 36.4 \%)$ versus the conventional technique $(0 \% ; \mathrm{P}<0.001)$. The incidence of eventful intubation with inverse intubation (81.8\%) was significantly greater than that with conventional intubation $(13.6 \%$; $\mathrm{P}<0.001)$. In difficult airways, the intubation success rate of conventional technique (90.9\%) was also significantly higher than that of inverse intubation (40.9\%; $\mathrm{P}=0.034)$. The median intubation time required for conventional intubation technique (20.6 seconds) was significantly shorter than that for inverse intubation (51.3 seconds; $\mathrm{P}=0.002)$. The number of difficult airway intubations was significantly higher with inverse technique $(n=12$; $54.5 \%)$ than with conventional technique (13.6\%; $\mathrm{P}=0.003)$. The incidence of eventful intubation was significantly higher in the inverse intubation group $(81.8 \%)$ than that in the conventional intubation group (36.4\%; $\mathrm{P}=0.002)$.

\section{Conventional intubation versus GlideScope intubation in a moving ambulance}

The intubation performance using conventional Macintosh and GlideScope laryngoscopes in a moving ambulance is summarised in Table 4 . In normal airways, the conventional intubation technique (95.5\%) and GlideScope laryngoscopy
(95.5\%) were associated with high success rates. The median intubation time with conventional technique (26.5 seconds) was shorter than that with GlideScope (31.0 seconds; $\mathrm{P}=0.012$ ). In difficult airways, both conventional technique (90.9\%) and GlideScope $(100 \%)$ were associated with high success rates. The median intubation time with conventional technique (20.6 seconds) was significantly shorter than that with GlideScope $(32.4$ seconds; $\mathrm{P}<0.001)$. None of the intubations with GlideScope in both normal and difficult airways was given Cormack-Lehane grade of $\geq 3$ but no statistical difference could be demonstrated in the grades when compared with conventional intubation in both normal $(\mathrm{P}=0.721)$ and difficult airways $(\mathrm{P}=0.180)$. There was an obvious trend for less eventful intubation with GlideScope (9.1\%) versus the conventional intubation group (36.4\%; $\mathrm{P}=0.069)$.

The relationship between the time required for intubation and AED experience is presented in Figure 4. An experienced doctor in AED required less time for conventional intubation in both normal $(\mathrm{P}=0.043)$ and difficult airways $(\mathrm{P}=0.019)$ in a static ambulance. Also, experienced doctors did better with conventional intubation than inverse intubation in normal airways in a moving ambulance $(\mathrm{P}=0.019)$.

Data on the doctors' perception of the new technique and device were also collected. Overall, two (9.1\%) and 17 (77.3\%) doctors thought that inverse intubation and GlideScope were, respectively, useful as adjuncts in normal airways, while one (4.5\%) and $19(86.4 \%)$ thought that inverse intubation and GlideScope were, respectively, useful in difficult airways.

TABLE 4. Comparison of success rate, intubation time, glottis visualisation grading, and eventful intubation rate with conventional Macintosh and GlideScope intubations in a moving ambulance

\begin{tabular}{|c|c|c|c|c|}
\hline & & $\begin{array}{c}\text { Conventional } \\
\text { intubation }(n=22)^{*}\end{array}$ & $\begin{array}{c}\text { GlideScope } \\
\text { intubation }(n=22)^{*}\end{array}$ & $P$ value \\
\hline \multirow[t]{7}{*}{ Normal airway } & Successful intubation $\leq 60$ seconds & $21(95.5)$ & $21(95.5)$ & 1 \\
\hline & Intubation time (seconds) & $26.5 \pm 14.1$ & $31.0 \pm 10.3$ & 0.012 \\
\hline & Cormack-Lehane grade $1 / 2 / 3 / 4$ & $16 / 6 / 0 / 0$ & $18 / 4 / 0 / 0$ & 0.721 \\
\hline & Eventful intubation $\dagger$ & $2(9.1)$ & $3(13.6)$ & 1 \\
\hline & Oesophageal intubation & 0 & 0 & 1 \\
\hline & Intubation $>60$ seconds & $1(4.5)$ & $1(4.5)$ & 1 \\
\hline & Incisor breakage & $2(9.1)$ & $2(9.1)$ & 1 \\
\hline \multirow[t]{7}{*}{ Difficult airway } & Successful intubation $\leq 60$ seconds & $20(90.9)$ & $22(100)$ & 0.488 \\
\hline & Intubation time (seconds) & $20.6 \pm 11.8$ & $32.4 \pm 14.7$ & $<0.001$ \\
\hline & Cormack-Lehane grade 1/2/3/4 & $12 / 7 / 3 / 0$ & $17 / 5 / 0 / 0$ & 0.180 \\
\hline & Eventful intubation & $8(36.4)$ & $2(9.1)$ & 0.069 \\
\hline & Oesophageal intubation & $2(9.1)$ & 0 & 0.488 \\
\hline & Intubation $>60$ seconds & 0 & 0 & 1 \\
\hline & Incisor breakage & $6(27.3)$ & $2(9.1)$ & 0.240 \\
\hline
\end{tabular}

* Data are presented as No., No. (\%), or median \pm interquartile range

† Both intubation $>60$ seconds and incisor breakage were reported in one case 
(a) Spearman's correlation coefficient $r=-0.435 ; \mathrm{P}=0.043$

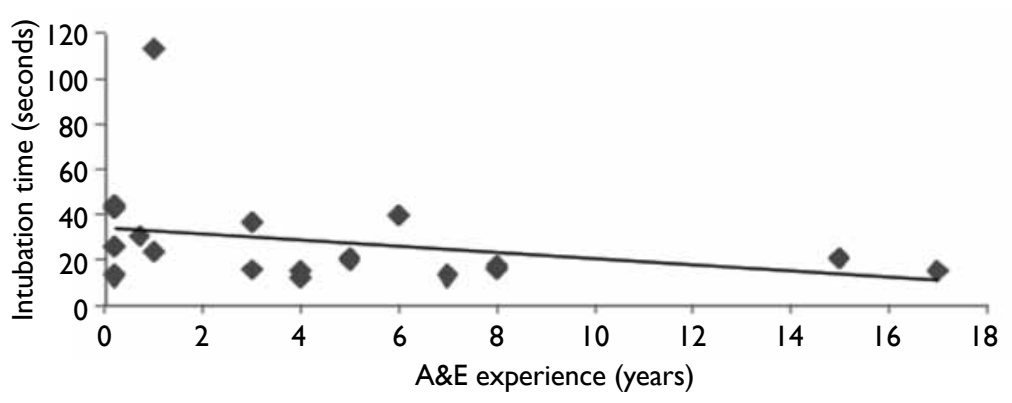

(b) Spearman's correlation coefficient $r=-0.523 ; \mathrm{P}=0.013$

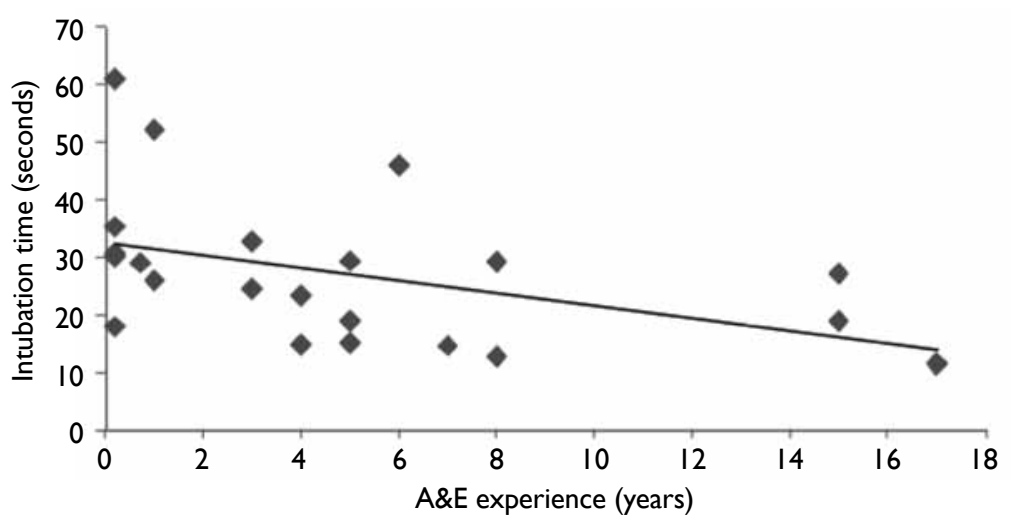

(c) Spearman's correlation coefficient $r=-0.506 ; \mathrm{P}=0.019$

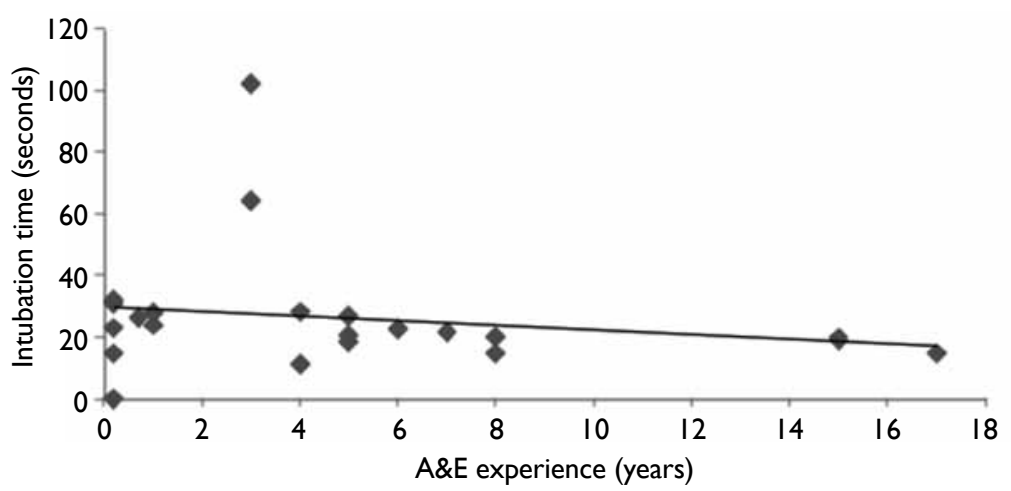

FIG 4. Correlation between intubation time for performing conventional intubation and working experience in the accident and emergency (A\&E) department (a) in a static ambulance in normal airways, (b) in a moving ambulance in normal airways, and (c) in a static ambulance in difficult airways factors including restricted space, continuous movement of the ambulance, and inadequate lighting are believed to adversely affect the enroute intubation compared with intubation in a controlled hospital setting. In our study, we found that the success rates of conventional Macintosh intubation in normal and difficult airways were high in static and moving ambulances. There was no significant difference in oesophageal intubation rate, intubation time, laryngeal visualisation scores, and incisor breakage rate with conventional Macintosh intubation in static and moving ambulances. The environment of a moving ambulance did not appear to hinder the ability of conventional Macintosh intubation in our experiment. Gough et $\mathrm{al}^{13}$ also recruited 20 emergency medical technicians at the advanced-intermediate level of EMT (Emergency Medical Technician) to perform intubation on a manikin in a moving ambulance and static station. They also found no significant difference in the success rates and time required for intubation between the two groups. Stopping an ambulance or a helicopter for en-route intubation may be impossible or dangerous in real life. Our study suggests that enroute intubation is feasible in an ambulance moving at a speed of $20 \mathrm{~km} /$ hour.

Inverse intubation has been proposed by Hilker and Genzwuerker ${ }^{3}$ as "an important alternative for intubation in the street". The technique was proven to be useful as adjunct in failed conventional intubation and an important backup position if access from behind the patient's head is impossible. ${ }^{4,5,14}$ In our study, we found that inverse intubation in an ambulance was associated with higher failure rate, prolonged intubation, and more complication rates versus conventional intubation. The clinical usefulness of this technique in a moving ambulance was not established in our study. Besides, one of the reported complications of inverse intubation is pharyngeal laceration. ${ }^{15}$ If this complication is not recognised, it could result in significant haemorrhage or potentially lethal infection. Individual experience is a significant determining factor for the success of the technique. During the experiment, we also found that it was quite inconvenient for the intubators who wore spectacles to perform inverse intubation as the spectacles were likely to fall off due to the peculiar posture required when performing the procedure. Inverse intubation would be a reasonable choice for trained rescuer who cannot position himself/herself to the space above the victim's (eg entrapment).

GlideScope has been shown to facilitate tracheal intubation by improving the laryngeal view in manikin studies, ${ }^{7-9}$ emergency settings, ${ }^{16-18}$ and a wide spectrum of selective surgeries. ${ }^{19-21}$ Struck et $\mathrm{al}^{6}$ conducted a retrospective observational study and survey of experiences in prehospital intubation for a 3 -year period. Around $15 \%$ of the 
patients presented with multiple traumas or failed intubation with conventional laryngoscopy and required intubation by GlideScope. In our study, we demonstrated high intubation success and low failure rates with GlideScope laryngoscopy, but the median time for intubation was slightly longer versus that with the conventional Macintosh laryngoscopy in normal airways $(\mathrm{P}=0.012)$ and difficult airways $(\mathrm{P}<0.001)$. The finding of longer intubation time with GlideScope was also demonstrated in previous studies. ${ }^{16,19,20}$ However, some studies found no difference in the intubation time. ${ }^{7,22}$ One study ${ }^{8}$ even found that GlideScope enables faster intubation in patients with cervical spine immobilisation. The wide range of results may be attributed to the differences in experience with using GlideScope, different study settings (manikin vs real patient), and different study scenarios (normal vs difficult airway). Piepho et $\mathrm{al}^{23}$ conducted a study among paramedics who used the Macintosh and GlideScope video laryngoscopes for intubating manikins. They found that the intubation time with GlideScope was longer than that with Macintosh in the first and second attempts of intubation. However, no significant difference in time required for intubation was observed in the subsequent attempts. This confirms a rapid learning curve for intubation with GlideScope. In another manikin study with 60 anaesthetists, GlideScope was found to have a steep learning curve for intubation but, after five attempts, differences in terms of time of endotracheal intubation persisted when compared with the Macintosh laryngoscopy ${ }^{24}$ In our study, there was a trend for less eventful intubation with GlideScope $(\mathrm{P}=0.069)$ in the setting of difficult airways. Thus, we recommend its use as a backup for en-route intubation, especially in difficult airway settings. In real-life practice of using GlideScope, the passage of endotracheal tube through the deeply curved and rigid stylet may be hindered. An assistant is required to thread the endotracheal tube into the trachea while the intubator holds the GlideScope in position. This is expected to be more difficult in an ambulance because of limited space.

This study had several limitations. Firstly, we used a manikin in our study rather than a real patient; thus, the results may not be transferrable to real patients. However, we believe that the use of new techniques and devices in airway management is not ethical in clinically unstable and emergency patients. A well-designed manikin-based study would be an acceptable choice for the aforementioned reasons. Secondly, only one of the difficult airway situations was tested in our study. Other difficult airway situations in daily practice such as limited mouth opening, tongue oedema, and presence of blood/ vomitus were not studied. Thirdly, there was the issue of learning curve associated with new techniques and devices. Overall, one (4.5\%) and eight (36.4\%) of the participants had previous experience of using inverse intubation and GlideScope in clinical settings, respectively. Although we demonstrated the use of inverse intubation and GlideScope and allowed participants to practise freely at least 1 week before the experiment, we cannot demonstrate the non-inferior result associated with the use of inverse intubation in a previous study. ${ }^{5} \mathrm{We}$ also observed that the intubation time for difficult airways in a moving ambulance was shorter than that for normal airways. The most likely explanation is the learning effect and intubation experience. The participants performed different intubation techniques in normal airways followed by the same techniques in difficult airways in a moving ambulance. The participants may have gained experience from working in a continuously moving environment. We suggest further studies with inverse intubation and GlideScope after a longer period of training and practice to examine for the reproducibility of these results. Fourthly, the study was performed inside our hospital which has imposed speed limits on vehicles moving on the road. Moving at a relatively slow speed of $20 \mathrm{~km} /$ hour was only possible in the chosen route as there were a number of turnarounds and road bumpers. Moreover, we limited the speed in order to avoid any danger to or fall of participants. Fifthly, GlideScope (model: GVL 4) for the experiment was chosen because it was the only model available in our hospital. Other models that are specifically designed for prehospital use such as Glidescope Ranger may be a better choice, if available. Lastly, the sample size of the study was relatively small and could have inadequate power to detect real differences between some comparison, for example, comparison of the eventful intubation rate between GlideScope and conventional intubation.

\section{Conclusions}

Our study demonstrates an overall high intubation success rate with conventional Macintosh and GlideScope laryngoscopes in a moving ambulance. The time required for intubation with GlideScope was longer than that with conventional laryngoscope. Application of GlideScope should be suggested as an adjunct for intubation in an ambulance in the presence of adequately trained staff. The high failure rate and prolonged time associated with the inverse intubation technique make it less useful than conventional intubation and GlideScope intubation unless the cranial access of the patient is restricted.

\section{Acknowledgements}

We would like to thank the Auxiliary Medical Service, the Hong Kong SAR Government for providing the ambulance and all physicians who participated in this experimental study. 


\section{References}

1. Helm M, Hossfeld B, Schäfer, Hoitz J, Lampl L. Factors influencing emergency intubation in the pre-hospital setting-a multicentre study in the German Helicopter Emergency Medical Service. Br J Anaesth 2006;96:67-71.

2. McIntosh SE, Swanson ER, McKeone A, Barton ED. Location of airway management in air medical transport. Prehosp Emerg Care 2008;12:438-42.

3. Hilker T, Genzwuerker HV. Inverse intubation: an important alternative for intubation in the streets. Prehosp Emerg Care 1999;3:74-6.

4. Hoyle JD Jr, Jones JS, Deibel M, Lock DT, Reischman D. Comparative study of airway management techniques with restricted access to patient airway. Prehosp Emerg Care 2007;11:330-6.

5. Robinson K, Donaghy K, Katz R. Inverse intubation in air medical transport. Air Med J 2004;23:40-3.

6. Struck MF, Wittrock M, Nowak A. Prehospital Glidescope video laryngoscopy for difficult airway management in a helicopter rescue program with anaesthetists. Eur J Emerg Med 2011;18:282-4.

7. Nakstad AR, Sandberg M. The GlideScope Ranger video laryngoscope can be useful in airway management of entrapped patients. Acta Anaesthesiol Scand 2009;53:125761.

8. Lim TJ, Lim Y, Liu EH. Evaluation of ease of intubation with the GlideScope or Macintosh laryngoscope by anaesthetists in simulated easy and difficult laryngoscopy. Anaesthesia 2005;60:180-3.

9. Benjamin FJ, Boon D, French RA. An evaluation of the GlideScope, a new video laryngoscope for difficult airways: a manikin study. Eur J Anaesthesiol 2006;23:517-21.

10. Cooper RM, Pacey JA, Bishop MJ, McCluskey SA. Early clinical experience with a new videolaryngoscope (GlideScope) in 728 patients. Can J Anaesth 2005;52:191-8.

11. Adnet F, Jouriles NJ, Le Toumelin P, et al. Survey of out-ofhospital emergency intubations in the French prehospital medical system: a multicenter study. Ann Emerg Med 1998;32:454-60.

12. Combes X, Jabre P, Jbeili C, at al. Prehospital standardization of medical airway management: incidence and risk factors of difficult airway. Acad Emerg Med 2006;13:828-34.

13. Gough JE, Thomas SH, Brown LH, Reese JE, Stone CK.
Does the ambulance environment adversely affect the ability to perform oral endotracheal intubation? Prehosp Disaster Med 1996;11:141-3.

14. Koetter KP, Hilker T, Genzwuerker HV, et al. A randomized comparison of rescuer positions for intubation on the ground. Prehosp Emerg Care 1997;1:96-9.

15. Smally AJ, Dufel S, Beckham J, Cortes V. Inverse intubation: potential for complications. J Trauma 2002;52:1005-7.

16. Platts-Mills TF, Campagne D, Chinnock B, Snowden B, Glickman LT, Hendey GW. A comparison of GlideScope video laryngoscope versus direct laryngoscopy intubation in the emergency department. Acad Emerg Med 2009;16:866-71.

17. Mosier JM, Stolz U, Chiu S, Sakles JC. Difficult airway management in the emergency department: GlideScope videolaryngoscopy compared to direct laryngoscopy. J Emerg Med 2012;42:629-34.

18. Sakles JC, Mosier JM, Chiu S, Keim SM. Tracheal intubation in the emergency department: a comparison of GlideScope ${ }^{\circ}$ video laryngoscopy to direct laryngoscopy in 822 intubations. J Emerg Med 2012;42:400-5.

19. Kim JT, Na HS, Bae JY, et al. GlideScope video laryngoscope: a randomized clinical trial in 203 paediatric patients. Br J Anaesth 2008;101:531-4.

20. Andersen LH, Rovsing L, Olsen KS. GlideScope videolaryngoscope vs. Macintosh direct laryngoscope for intubation of morbidly obese patients: a randomized trial. Acta Anaesthesiol Scand 2011;55:1090-7.

21. Griesdale DE, Liu D, McKinney J, Choi PT. Glidescope video-laryngoscopy versus direct laryngoscopy for endotracheal intubation: a systematic review and metaanalysis. Can J Anaesth 2012;59:41-52.

22. Teoh WH, Sexena S, Shah MK, Sia AT. Comparison of three videolaryngoscopes: Pentax Airway Scope, C-MAC, Glidescope vs the Macintosh laryngoscope for tracheal intubation. Anaesthesia 2010;65:1126-32.

23. Piepho T, Weinert K, Heid FM, Werner C, Noppens RR. Comparison of the $\mathrm{McGrath}^{\circ}$ Series 5 and GlideScope ${ }^{\circ}$ Ranger with the Macintosh laryngoscope by paramedics. Scand J Trauma Resusc Emerg Med 2011;19:4.

24. Savoldelli GL, Schiffer E, Abegg C, Baeriswyl V, Clergue F, Waeber JL. Learning curves of the Glidescope, the McGrath and the Airtraq laryngoscopes: a manikin study. Eur J Anaesthesiol 2009;26:554-8. 